\title{
Hydrodynamic signal perception by the copepod Oithona plumifera
}

\author{
Houshuo Jiang ${ }^{1, *}$, Gustav-Adolf Paffenhöfer ${ }^{2, * *}$ \\ ${ }^{1}$ Department of Applied Ocean Physics and Engineering, Woods Hole Oceanographic Institution, Woods Hole, \\ Massachusetts 02543, USA \\ ${ }^{2}$ Skidaway Institute of Oceanography, 10 Ocean Science Circle, Savannah, Georgia 31411, USA
}

\begin{abstract}
Spatio-temporal hydrodynamic signal fields were quantified for ambush-feeding Oithona plumifera females sensing motile Strobilidium ciliates. First, videotaped Oithona-ciliate encounters were image-analyzed to retrieve ciliate trajectories, O. plumifera attack kinematics and reaction distances to the ciliates. Second, using computational fluid dynamics (CFD), flow disturbances created by swimming ciliates were examined for 5 common ciliary forcing schemes. Third, using the CFD results and measured ciliate trajectories as inputs, a hydrodynamic model was developed to calculate ciliate-generated hydrodynamic signal patterns for observed encounters. Wide variance was found in measured reaction distances. Good correlations existed between measured predator attack kinematics and measured pre-attack prey locations. Moreover, data analysis showed that $O$. plumifera preferred small attack angles, presumably to enhance capture success. From hydrodynamic modeling, several distinct spatio-temporal hydrodynamic signal patterns were identified, and estimated hydrodynamic signal strengths immediately prior to attack were all above a minimum required signal level but differed substantially in magnitude. These results support the notion that by monitoring and recognizing the spatio-temporal pattern of ciliate-created flow disturbances, O. plumifera can perceive and project the ciliate's instantaneous location and velocity, and hence precisely time its attack when the ciliate reaches a location where it can most easily be captured. Instead of reacting to a constant signal strength, O. plumifera females adapt their capture behaviors to perceived signal patterns. CFD simulations also revealed species-specific flow patterns and spatial decays in hydrodynamic disturbances created by swimming protists. The predator may use this species-specific information to distinguish among prey species.
\end{abstract}

KEY WORDS: Oithona plumifera · Ciliate · Predator-prey interaction - Hydrodynamic signal perception · Spatio-temporal pattern · Hydrodynamic modeling · Capture difficulty

\section{INTRODUCTION}

Mechanoreception is the primary sense used by predatory copepods to perceive their prey (e.g. Strickler \& Bal 1973, Kerfoot 1978, Yen \& Strickler 1996, Fields \& Yen 1997, Visser 2001, Bundy \& Vanderploeg 2002, and references therein). Predatory copepods are able to remotely detect and adequately respond to prey, presumably by using mechanoreceptors (setae) on their first antennae (A1) to sense preyinduced hydrodynamic disturbances (e.g. Strickler 1975, Yen et al. 1992, Fields et al. 2002). Based on observations of attacks by Cyclops on swimming Bos- mina, Kerfoot (1978) surmised that the predator may become aware of the prey long before it initiates an attack on the prey. The predator must decide whether or not to attack, project speed and direction of the approaching prey, and evaluate attack orientation and speed (if the predator decides to attack), all within a short time interval after the prey is perceived. Kerfoot observed that the predator waited until the prey reached a location where a capture attempt could more readily succeed before attacking (Fig. 7 in Kerfoot 1978).

The hydrodynamic signals perceived by a predatory copepod may vary spatially and temporally because: 
(1) the distance between the predator and the prey may vary with time; (2) the prey may swim at changing speed and/or direction (e.g. swimming along a curved spiral trajectory; Svensen \& Kiørboe 2000, Broglio et al. 2001); (3) the prey may switch its swimming behavior (e.g. Kerfoot 1978, Fields \& Yen 1997); and (4) the predator may also switch its swimming behavior (e.g. Bundy et al. 1998). Thus, the hydrodynamic signal field should consist of certain spatio-temporal patterns perceived by the predatory copepod. We hypothesize that by monitoring the spatially and temporally varied hydrodynamic signal field (and recognizing the signal patterns), the predatory copepod is able to project the trajectory as well as the instantaneous swimming velocity of the prey, and then to respond accordingly (see also Zaret 1980). To our knowledge, no previous study has characterized such spatio-temporal signal patterns for real predator-prey interactions.

Planktonic cyclopoid copepods of the genus Oithona are of ecological importance in oligotrophic environments (Paffenhöfer 1993, Gallienne \& Robins 2001), and feed mainly on motile prey (Atkinson 1995, Nakamura \& Turner 1997, Castellani et al. 2005). Without creating feeding currents, Oithona spp. employ an ambush feeding strategy aided by mechanoreceptive setae covering their entire body (Paffenhöfer 1993, 1998, Kiørboe \& Visser 1999). Previously, behavioral observations have been made for $O$. similis adult females preying on the heterotrophic dinoflagellate Gymnodinium dominans (Svensen \& Kiørboe 2000) and for $O$. plumifera adult females preying on the dinoflagellate G. nelsoni and on nauplii of the copepod Paracalanus aculeatus (Paffenhöfer \& Mazzocchi 2002). We report observations of O. plumifera adult females feeding on the swimming ciliates Strobilidium spp. Using an empirical modeling approach, we identified the prey-created hydrodynamic signal patterns and investigated the role of the signal patterns in shaping the predator's prey perception and attack behavior.

\section{MATERIALS AND METHODS}

Collection and culture of organisms. Ciliates Strobilidium spp. were collected from the southeastern US continental shelf and kept in culture, with the flagellates Isochrysis galbana and Rhodomonas spp. offered as food at a total of 20 to $40 \mu \mathrm{g} \mathrm{Cl}^{-1}$. Oithona plumifera specimens were obtained, as described in an earlier paper (Paffenhöfer \& Mazzocchi 2002), from outer shelf oblique tows with $100 \mu \mathrm{m}$ mesh and $4 \mathrm{l}$ cod ends. Subsequently, laboratory rearing experiments were performed under controlled conditions to obtain nauplii, copepodids and adult females of $O$. plumifera. The copepods were fed flagellates, dinoflagellates and ciliates at environmental concentrations. These rearing experiments were conducted at $20^{\circ} \mathrm{C}$ under a $12: 12 \mathrm{~h}$ light:dark cycle on a plankton wheel rotating at $\sim 0.3 \mathrm{rpm}$.

Video observations. The empirical study included observing and tape recording interactions between adult females of Oithona plumifera (as predators) and ciliates of the genus Strobilidium (as prey) at in situ prey concentrations (i.e. 5 to 15 ciliates $\mathrm{ml}^{-1}$ ). The predator-prey interactions, contained inside a cuvette (1 to 3 l), were videotaped on S-VHS at 60 frames $\mathrm{s}^{-1}$ for 1 to $2 \mathrm{~h}$. The tape recording was conducted in the dark using an infrared laser as illumination source. The optical setup for the recording was $2 \mathrm{D}$, with a single camera and a spatial resolution of $\sim 15 \mu \mathrm{m}$.

Video image analysis. Although hundreds of Oithona-ciliate encounter events were recorded in the present study, we analyzed only those events in which both the Oithona plumifera body region for sensing and the prey swimming track were on the focal plane during the whole encounter period. The videotapes were first evaluated on a TV monitor to sort out 26 infocus encounter events that were then digitized into sequences of video images at $720 \times 480$ pixels with 8 bits of pixel depth using image-grabbing software (Adobe Premiere Pro v1.5). The only criterion for selecting the 26 events was their good focus during the whole encounter period. The video images were analyzed frame by frame using Adobe Illustrator v8.0 by reading pixel numbers manually. Because O. plumifera maintained its body posture and was virtually motionless before it attacked a ciliate, we were able to draw a constant body profile for the copepod (or, more precisely, for the identified copepod sensory region with which the ciliate was interacting). Relative to this constant profile which was used as a frame of reference, we then obtained the swimming trajectory of the ciliate as a time series of its instantaneous centroid positions. From this time series, we further calculated the swimming velocity (i.e. speed and direction) history of the ciliate. The location and surface shape profile of the sensory region of the copepod was also determined by reading pixel numbers manually. By analyzing and contrasting the 2 image frames right before and after an attack, a few behavioral characteristics, including $O$. plumifera attack distance, attack speed and attack angle, were determined (Fig. 1, Table 1).

Computational fluid dynamics (CFD) modeling of the flow generated by a swimming ciliate. To quantify the spatio-temporal hydrodynamic signals created by a ciliate swimming near an Oithona plumifera female, we needed to 'paint' the ciliate-created hydrodynamic disturbances onto the observed trajectory of the ciliate. 


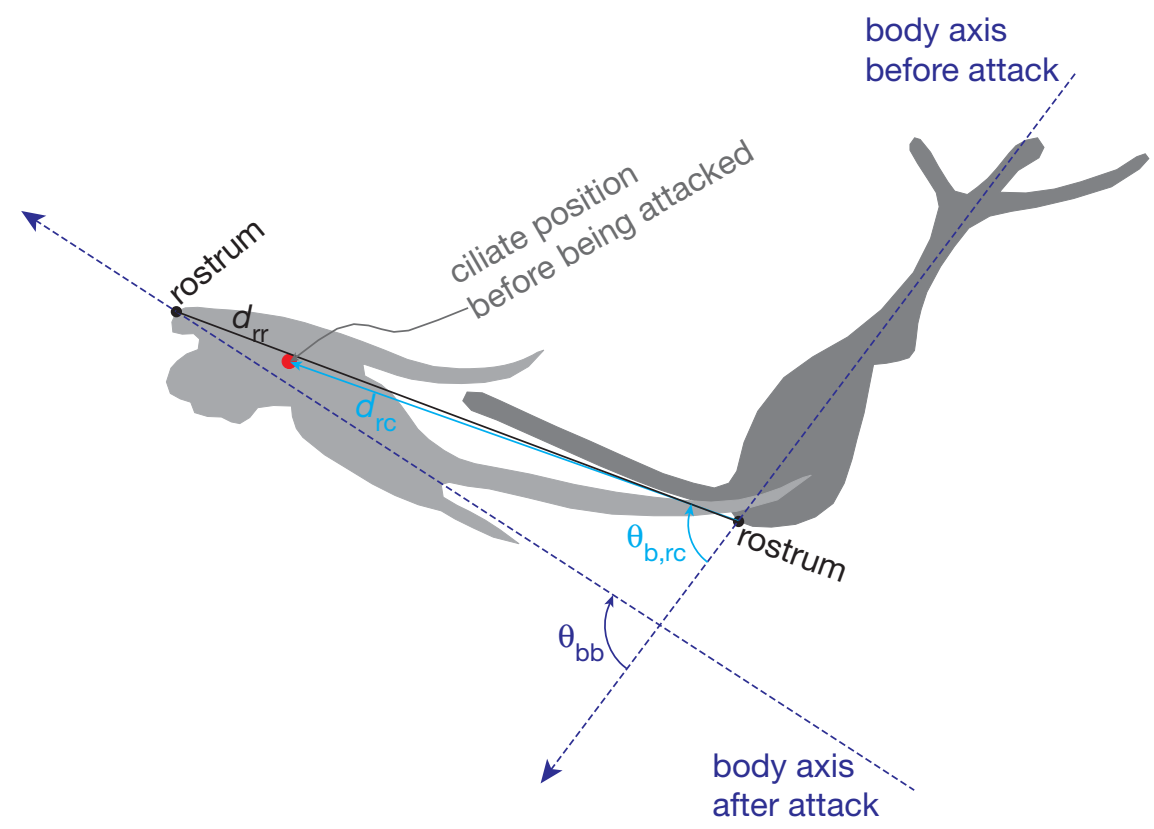

Fig. 1. Oithona plumifera. Behavioral characteristics of an attack made by a female on a swimming Strobilidium ciliate. Behavioral characteristics are defined in Table 1

Table 1. Oithona plumifera. Definitions of behavioral characteristics of adult females preying on swimming ciliates Strobilidium spp.

\begin{tabular}{|ll|}
\hline Characteristic & \multicolumn{1}{c|}{ Definition } \\
\hline$u_{\text {ciliate }}$ & $\begin{array}{l}\text { Ciliate swimming speed just before attack } \\
d_{\mathrm{rc}}\end{array}$ \\
$\theta_{\mathrm{b}, \mathrm{rc}}$ & $\begin{array}{l}\text { Distance between the copepod's rostrum and the } \\
\text { ciliate's position just before an attack (Fig. 1) }\end{array}$ \\
& $\begin{array}{l}\text { Angle formed between the copepod's body axis } \\
\text { and the line drawn from the copepod's rostrum to } \\
\text { the ciliate's position just before an attack (Fig. 1) }\end{array}$ \\
& $\begin{array}{l}\text { Shortest distance between the ciliate and the } \\
\text { copepod just before an attack, i.e. the reaction } \\
\text { distance }\end{array}$ \\
$U_{\mathrm{attack}}$ & $\begin{array}{l}\text { Maximum speed the copepod's rostrum traveled } \\
\text { during an attack }\end{array}$ \\
$d_{\mathrm{rr}}$ & $\begin{array}{l}\text { Distance between the copepod's rostrum posi- } \\
\text { tions before and after an attack (Fig. 1) }\end{array}$ \\
$\theta_{\mathrm{bb}}$ & $\begin{array}{l}\text { Angle formed between the copepod's body axis } \\
\text { before and after an attack (Fig. 1) }\end{array}$ \\
\hline
\end{tabular}

Before doing so, we investigated the properties of the flow field associated with a self-propelling ciliate using a CFD model.

When swimming at a constant velocity, a neutrally buoyant ciliate receives no net force from the surrounding water. According to the multipole expansion theory for Stokes flow surrounding an immersed particle, the far disturbance flow for such a force-free, self-propelling 'particle' decays at least as $1 / r^{2}$ (cf. Pozrikidis 1992, p. 46). To model the flow disturbances created by a force-free, self-propelling zooplankter, Visser (2001) proposed a stresslet model that decays exactly as $1 / r^{2}$ in the far field. However, the stresslet strength of Visser's model was confined to a specific form, i.e. the 2 opposing point forces are of the same magnitude of $6 \pi \mu a U$, applied along the same line aligned with the swimming direction, and separated by a distance of $2 a$ (where $\mu$ is the dynamic viscosity of the fluid, $a$ is the effective radius of the zooplankter, and $U$ is the swimming velocity). The product of the force magnitude and the separation distance (i.e. $6 \pi \mu a U \times 2 a=$ $\left.12 \pi \mu a^{2} U\right)$, defined as the stresslet strength, determines the bulk level of velocity magnitudes in the stresslet flow field. In contrast, Svensen \& Kiørboe (2000) used a similar stresslet model but with a stresslet strength that is $2 \pi(\sim 6.28 \times)$ stronger than that of Visser's. Different choices of the stresslet strength certainly led to different levels of velocity magnitudes in the stresslet flow fields (i.e. the hydrodynamic signal fields). We suggest that the stresslet strength may be adjusted using information on how the microorganism propels itself, especially its distribution of propulsive forces over the surrounding water. We later use data from our CFD modeling of the flow surrounding a steadily swimming ciliate to calibrate the stresslet strength.

The present CFD modeling was based on the traction-layer model for ciliary propulsion (Keller et al. 1975, Wu 1976, 1977). The basic modeling concept was to replace the discrete forcing associated with ciliary movement, with an equivalent continuum distribution of body force within the ciliary layer. The original traction-layer model was for an infinite, flat layer of distributed body force with planar beating patterns by the cilia, which allowed an analytical treatment. However, an analytical treatment is, in general, impossible for finite, 3D body morphology and for more realistic ciliary beating patterns, although one can implement the traction-layer model into CFD numerical simulations. As a first step, we chose to simulate a simplified situation of the flow disturbances created by a spherical model ciliate of cell radius $a$, covered with a ciliary layer of thickness 1 , swimming at a constant velocity $U$, along a straight line (which was taken as the axisymmetric axis). As the flow is axisymmetric, only a meridian plane was taken as the computational domain and a symmetry condition was specified on the axisym- 
metric axis (Fig. 2f). The span of the domain was $(-100 a, 100 a)$ in the axial $x$ direction, and $(0,100 a)$ in the radial $r$ direction, with the center of the spherical ciliate as the origin of the coordinate system. A cylindrical polar coordinate system was used, with $r$ being the radial distance from the $x$-axis. Because of axisymmetry, the flow pattern is independent of the azimuthal coordinate $\varphi$, and is identical in all planes containing the $x$-axis. The computational domain was discretized into 750 quadrilateral control volumes (CVs) immediately adjacent to the cell surface and into 161072 triangular CVs that were stretched radially outward from the outer boundary of the quadrilateral CVs. On the quadrilateral CVs, a steady distribution of body force $\mathbf{F}(x, r)$ was applied to model the forcing due to ciliary beating, with the axial component, $F_{X}(X, r)$, and the radial component $F_{r}(X, r)$, specified as:

$$
\begin{aligned}
& F_{x}(x, r)=f \sin (\pi \eta) \frac{r}{\sqrt{X^{2}+r^{2}}} \\
& F_{r}(x, r)=-f \sin (\pi \eta) \frac{x}{\sqrt{x^{2}+r^{2}}}
\end{aligned}
$$

where $\eta=\frac{\sqrt{x^{2}+r^{2}}-a}{l}, a, x$ and $r$ are as defined above, and $f$ is a constant forcing density in $\mathrm{N} \mathrm{m}^{-3}$. Such a specification of the forcing follows the analytical solution of Wu (1977) for an infinite, plane ciliary layer. Wu's solution provides the optimum distribution of the average ciliary continuum force under the condition of minimum power required for fixed mean square force.

Using the above-described CFD model, we considered 5 ciliary forcing schemes: (1) the whole ciliate surface is covered by cilia (Fig. 2a); (2) a single cilium (flagellum) modeled by a point force $\mathbf{F}$ trails the cell body (Fig. 2b); (3) the posterior surface of the ciliate body is covered by cilia, with $\mathbf{F}(x, r)$ being non-zero only in the polar angle range from 0 to $36^{\circ}$ (Fig. 2c); (4) the equatorial surface of the ciliate is covered by cilia, with $\mathbf{F}(x, r)$ being non-zero only in the polar angle range from 72 to $108^{\circ}$ (Fig. 2d); and (5) the anterior surface of the ciliate is covered by cilia, with $\mathbf{F}(x, r)$ being non-zero only in the polar angle range from 144 to $180^{\circ}$ (Fig. 2e). Although seemingly abstract, these 5 forcing schemes are all probable in the real world [see text books by Fenchel (1987) and Hausmann et al. (2003)]. The 5th ciliary forcing scheme (Fig. 2e) was considered similar to that employed by ciliates of the genus Strobilidium (Montagnes \& Taylor 1994).

An inlet velocity boundary condition established by specifying a rightward velocity of magnitude $U$ was imposed on the left outer boundary of the computational domain, which modeled the leftward swimming velocity of magnitude $U$ of the ciliate under a transformation between 2 frames of reference. A no-slip boundary con- dition was specified at the cell surface. The flow surrounding the spherical ciliate was obtained by solving the Navier-Stokes equations numerically under the above-described forcing and boundary conditions using a commercially available, finite-volume code, FLUENT (v6.2.16). We achieved favorable comparisons between FLUENT results and several Stokes flow analytical solutions as we did in Jiang et al. (1999). The drag $D$ acting on the cell surface was then obtained by determining the axial component of the integral of pressure and shear stress over the cell surface. The thrust $T$ was equal to the axial component of the volume integral of $\mathbf{F}(X, r)$. For a given $U$, the forcing density $f$ was determined by equating $D$ and $T$ (i.e. to reach a steady, self-propelling state). This was achieved by trial and error iteration, and 20 iterations were needed to attain $D=T$ to at least 7 significant digits.

Calculating the hydrodynamic signal field. As described before, the stresslet model consists of 2 point forces ( 2 stokeslets) that are of the same intensity (i.e. $6 \pi \mu a U)$ but opposite directions - one being applied along, and the other against, the instantaneous swimming direction of the ciliate. The application points of the 2 point forces are separated by a given distance, with its middle point coincident with the instantaneous center of the ciliate. The separation distance was first calibrated by comparing the stresslet flow field with the flow field obtained from CFD, such that the 2 flow fields had approximately the same level of flow velocity within the Oithona reaction range ( 10 to 30 a from the center of the ciliate based on our observations). The stresslet model with a calibrated separation distance was then used to calculate the hydrodynamic signal field (i.e. the flow disturbance field). The calculation procedure is as follows: by assuming quasisteadiness, we substituted $U$ with $U(t)$, the measured time history of swimming velocity magnitude of the ciliate, and calculated flow disturbance as a timedependent field. The stresslet flow field (equivalent to a linear combination of 2 stokeslet flow fields) was required to satisfy the no-slip boundary condition imposed at the surface of a specified sensory region of the Oithona plumifera female (e.g. the A1 front portion, the A1 tip, or the mouthparts). By approximating the A1 front portion to be an infinite plane wall and the A1 tip or the mouthparts to be a small sphere of suitable size, we were able to make use of 2 Green's functions (which vanish at the solid boundaries) to achieve an analytical treatment of the flow disturbance field. The 2 Green's functions are: (1) for flow bounded by an infinite plane wall (cf. Pozrikidis 1992, p. 84-86); and (2) for an infinite flow bounded internally by a solid sphere (cf. Pozrikidis 1992, p. 87-88). The rest of the solution procedure was similar to that in Jiang \& Paffenhöfer (2004). 

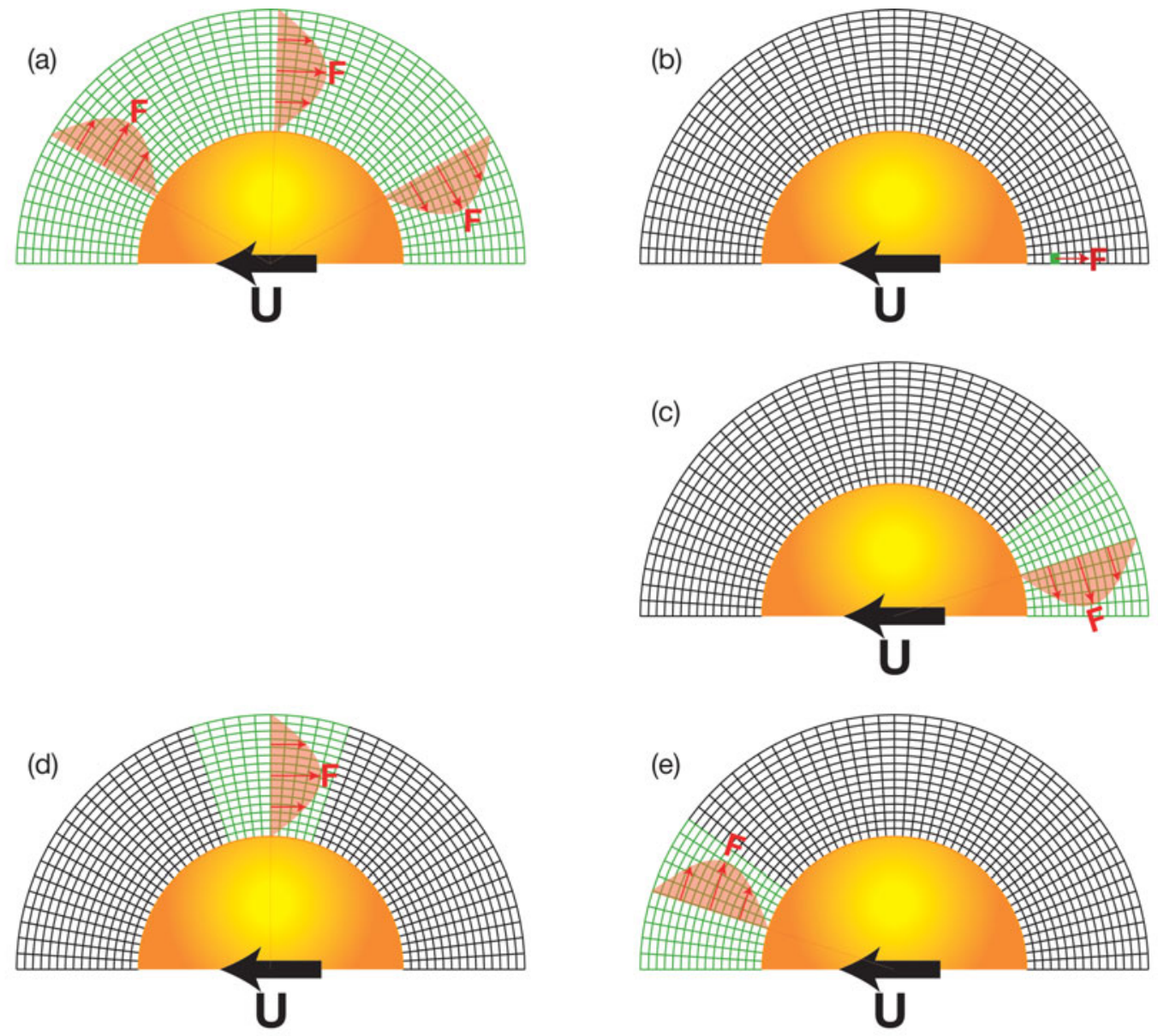

(f)

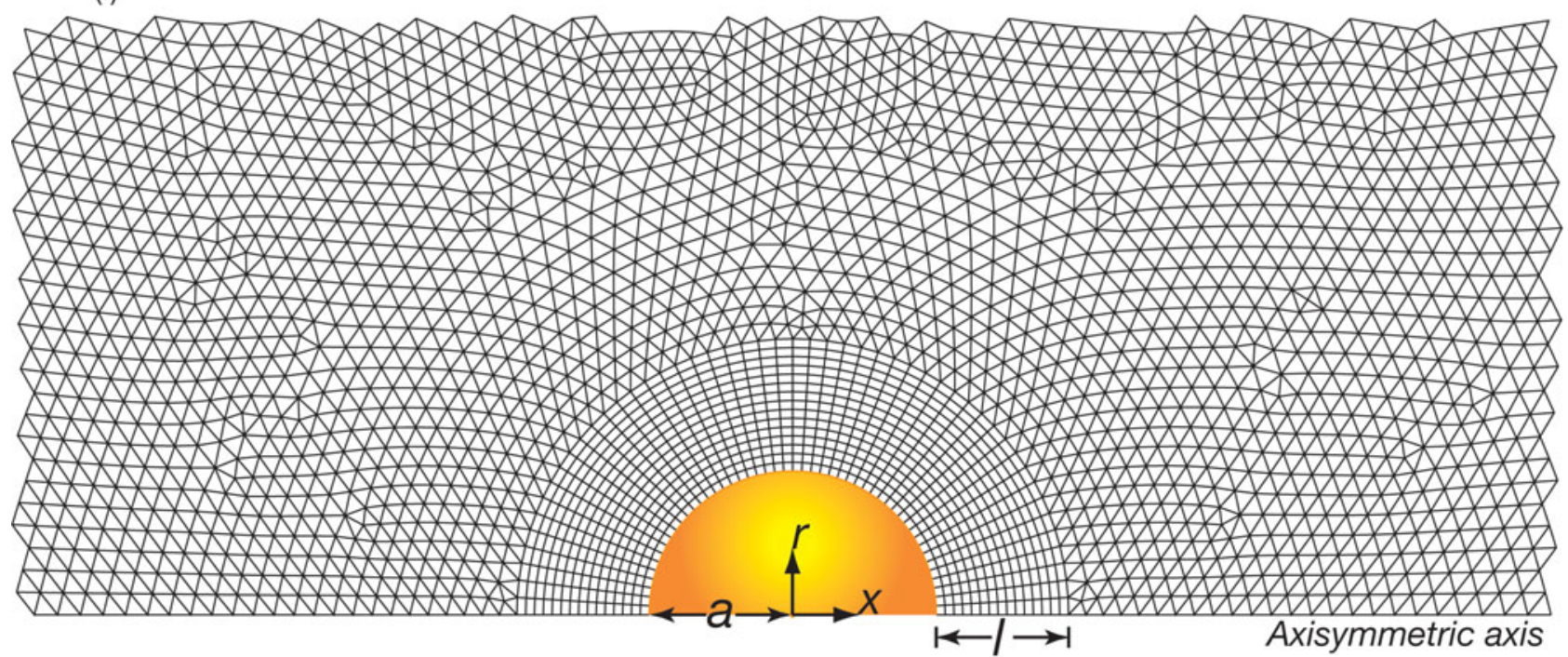

Fig. 2. Axisymmetric computational fluid dynamics (CFD) model for simulating the flow disturbances created by a spherical model ciliate of cell radius $a$, and covered with a ciliary layer of thickness 1 , swimming leftward at a constant speed $U$ (i.e. the swimming velocity vector $\mathbf{U}) . x$ and $r$ refer to the axial and radial directions, respectively. Five ciliary forcing schemes are considered (see 'Materials and methods'). In (a) to (e), the meshes in green color immediately surrounding the body mark the ciliary layer on which a distributed body force field $\mathbf{F}$ is applied to model the thrust exerted by ciliary beating. The 5 cilia/flagellum forcing schemes share the same grid as shown in (f) 


\section{RESULTS}

\section{Description of encounter events}

In 24 of the 26 chosen events (Table 2), the female Oithona plumifera adopted a horizontal to upsidedown position before attacking (Fig. 3). The copepod assumed a posture with its anterior pointing upward in only 2 events (not shown). On the prey side, the ciliates swam along a rather straight line in 17 events (e.g. Fig. $3 \mathrm{a}-\mathrm{d}, \mathrm{g}, \mathrm{i} ;$ Ciliate B in Fig. 3j; Ciliate in Fig. 3k), circled or spiraled in 5 events (e.g. Fig. 3e,f,h; Ciliate A in Fig. $3 \mathrm{j}$ ), and zigzagged in 4 events (not shown).

Oithona plumifera females possessed a 3D attack volume, i.e. they were able to perceive and capture swimming ciliates from all around their bodies or from almost any angle. The prey swam from the outer perimeter into $O$. plumifera's sensory regions in 18 events (e.g. Fig. 3a-d,f,g,i,l; Ciliate B in Fig. 3j; Ciliate in Fig. 3k), whereas they initiated their swimming motion at places very close to O. plumifera's sensory

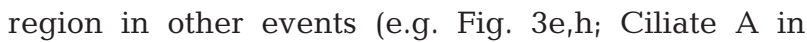
Fig. 3j; Copepod nauplius in Fig. 3k). We also observed that $O$. plumifera encountered 2 motile prey nearly simultaneously in 3 events. In 1 event (Fig. 3j), the copepod attacked the ciliate swimming along a straight trajectory but ignored the one swimming along a spiraling trajectory. In the other 2 events (Fig. 3k,1), the copepods ignored the prey located near the caudal rami region but attacked the one in front of the A1. In the latter 2 events, the 2 ignored prey must have been detected by the copepods as they bumped into the copepods' bodies. However, when a ciliate bumped into the copepod's caudal rami and no other prey was present, the copepod quickly turned around and captured the ciliate (Fig. 3i).

\section{Measured behavioral characteristics}

Wide variances were found in all measured behavioral characteristics (Table 3). Specifically, in events where Oithona plumifera A1s were the sensory region, reaction distances ranged from 0 to $0.71 \mathrm{~mm}$ with a mean of $0.38 \pm 0.20 \mathrm{~mm}$ (SD) (Table 4). Even larger standard deviations were obtained for events where $O$. plumifera mouthparts or prosomes were the sensory region, and for events where higher ciliate concentrations were offered (Table 4).

Post-attack body postures and positions of Oithona plumifera were usually different from pre-attack ones (Fig. 1). Measured O. plumifera attack kinematics, including attack distance and attack angle, show good correlations with the parameters measured to describe the pre-attack location of the prey (Fig. $4 \mathrm{a}, \mathrm{b}$ ). This cor- respondence indicates that attack by $O$. plumifera is an oriented response similar to that found by Doall et al. (2002) for Euchaeta rimana attacking smaller copepod species. Thus, O. plumifera is capable of locating prey accurately and of correspondingly adjusting its attack direction and distance. In terms of $O$. plumifera body rotation during an attack, our observations show 2 extreme situations along with many intermediate situations: (1) the ciliate swam along a path directly aimed at the copepod's mouthparts (Fig. 3g), with the copepod responding by not initiating attack until the ciliate virtually arrived at its mouthparts, and resulting in almost no body rotation being involved; and (2) the ciliate bumped into the copepod's caudal rami, with the copepod responding by immediately rotating its body by almost $180^{\circ}$ in order to capture the prey (Fig. 3i). Larger body rotations required more effort from the copepods, resulting in copepods experiencing more difficulty in capturing prey. Data also show higher frequency of small attack angles than short attack distances (Fig. 4c,d). This suggests that O. plumifera prefers small body rotations, presumably to reduce capture difficulty.

\section{CFD modeling of the flow generated by a swimming ciliate}

The cell diameters of Strobilidium spp. were 35 to 60 and 20 to $30 \mu \mathrm{m}$ with and without cilia. Therefore, we chose $a=15.0 \mu \mathrm{m}$, and $l=13.8 \mu \mathrm{m}$ as the parameter set for ciliate size. Their swimming speeds were $<10 \mathrm{~mm}$ $\mathrm{s}^{-1}$ (Table 2). Based on these values, the Reynolds number should be $<0.23$, defined as:

$$
\operatorname{Re} \equiv \frac{\rho U 2 a}{\mu}
$$

where $U$ is the swimming speed, $\mu$ is the dynamic viscosity $\left(=1.390 \times 10^{-3} \mathrm{~kg} \mathrm{~m}^{-1} \mathrm{~s}^{-1}\right)$, and $\rho$ is the density $\left(=1.027 \times 10^{3} \mathrm{~kg} \mathrm{~m}^{-3}\right)$ of seawater at $10^{\circ} \mathrm{C}$, a salinity of 35 , and 1 normal atmosphere. Thus, inertia is not as important as viscous effects, and one can present all flow velocity results as normalized by $U$.

CFD modeling shows that the near- and far-field flow patterns and the spatial decay of the hydrodynamic disturbances created by a swimming ciliate are all sensitive to the way the ciliate propels itself, and especially to its distribution of propulsive forces over the surrounding water, i.e. they vary for different ciliary forcing schemes (Figs. 5 to 7). In cases where the whole ciliate surface is covered by cilia (Fig. 2a) or where the equatorial surface is covered by cilia (Fig. 2d), the flow patterns are not dipole-like at all (Figs. 5a,d \& 6a,d) and therefore differ from that of the stresslet model (Fig. 6f). In terms of spatial decay, the flow attenuates 
Table 2. Oithona plumifera. Information on the encounter events between adult females and swimming ciliates Strobilidium spp.

\begin{tabular}{|c|c|c|c|c|}
\hline Event \# & Description of encounter events & $\begin{array}{l}\text { Ciliate } \\
\text { swimming } \\
\text { velocity } \\
\left(\mathrm{mm} \mathrm{s}^{-1}\right)\end{array}$ & $\begin{array}{l}\text { Female- } \\
\text { ciliate } \\
\text { encounter } \\
\text { time (s) }\end{array}$ & $\begin{array}{l}\text { Ciliate } \\
\text { capture } \\
\text { success }\end{array}$ \\
\hline $\begin{array}{l}1 \\
\text { (Fig. 3a) }\end{array}$ & $\begin{array}{l}\text { Ciliate swam rather unidirectionally and constantly along a trajectory } \\
\text { parallel to female's A1. }\end{array}$ & $3.9-5.4$ & 0.37 & Yes \\
\hline 2 & Ciliate swam slowly away from female's A1. & $0.3-1.6$ & 0.53 & Yes \\
\hline 3 & $\begin{array}{l}\text { Ciliate accelerated from } 0 \text { velocity and swam in a looped trajectory } \\
\text { along female's A1. }\end{array}$ & $0.0-7.5$ & 0.20 & Yes \\
\hline 4 & $\begin{array}{l}\text { Ciliate swam rather unidirectionally and constantly along female's } \\
\text { A1 (or A1 tip). }\end{array}$ & $6.1-9.1$ & 0.67 & Yes \\
\hline $\begin{array}{l}5 \\
\text { (Fig. 3b) }\end{array}$ & $\begin{array}{l}\text { Ciliate swam rather unidirectionally, constantly and perpendicularly } \\
\text { towards female's A1 back portion. }\end{array}$ & $5.3-9.9$ & 0.73 & Yes \\
\hline 6 & Ciliate swam towards female's A1 front portion. & $4.5-4.9$ & 0.23 & Yes \\
\hline $\begin{array}{l}7 \\
\text { (Fig. 3c) }\end{array}$ & $\begin{array}{l}\text { Ciliate accelerated from } 0 \text { velocity, swam rather unidirectionally and } \\
\text { constantly towards, and finally bumped into, female's A1 tip. }\end{array}$ & $0.0-4.8$ & 0.47 & Yes \\
\hline 8 & $\begin{array}{l}\text { Ciliate swam rather unidirectionally and constantly towards the region } \\
\text { anterior to female. }\end{array}$ & $5.4-7.2$ & 0.37 & Yes \\
\hline $\begin{array}{l}9 \\
\text { (Fig. 3k) }\end{array}$ & $\begin{array}{l}\text { Ciliate accelerated from } 0 \text { velocity and swam towards the region anterior } \\
\text { to female. Simultaneously, a copepod nauplius jumped intermittently } \\
\left(0-11.9 \mathrm{~mm} \mathrm{~s}^{-1}\right) \text { along a looped trajectory near female's egg sac region } \\
\text { and contacted female's body, but was not attacked. }\end{array}$ & $\begin{array}{l}\text { Ciliate: } \\
0.0-9.6 \\
\text { Nauplius: } \\
0-11.9\end{array}$ & $\begin{array}{l}\text { Ciliate: } \\
0.27 \\
\text { Nauplius: } \\
0.27\end{array}$ & $\begin{array}{l}\text { Ciliate: } \\
\text { Yes } \\
\text { Nauplius: } \\
\text { No }\end{array}$ \\
\hline $\begin{array}{l}10 \\
\text { (Fig. 3d) }\end{array}$ & $\begin{array}{l}\text { Ciliate swam rather unidirectionally and constantly passing by female's } \\
\text { A1 tip. }\end{array}$ & $3.6-5.1$ & 0.40 & No \\
\hline 11 & Ciliate accelerated from 0 velocity and swam passing by female's A1 tip. & $0.0-6.8$ & 0.30 & No \\
\hline $\begin{array}{l}12 \\
\text { (Fig. 3e) }\end{array}$ & Ciliate circled nearby female's A1 tip at $\sim 0.18 \mathrm{~s} \mathrm{cycle}^{-1}$ for a few seconds. & $1.7-4.4$ & 5.97 & Yes \\
\hline 13 & $\begin{array}{l}\text { Ciliate accelerated from } 0 \text { velocity and circled intermittently nearby } \\
\text { female's A1 tip. }\end{array}$ & $0.0-3.6$ & 0.67 & Yes \\
\hline $\begin{array}{l}14 \\
\text { (Fig. 3f) }\end{array}$ & $\begin{array}{l}\text { Ciliate swam in an irregular helical trajectory upward towards the region } \\
\text { anterior to female for } \sim 7.5 \mathrm{~s} \text {. }\end{array}$ & $0.4-3.9$ & 7.43 & Yes \\
\hline $\begin{array}{l}15 \\
\text { (Fig. 3j) }\end{array}$ & $\begin{array}{l}\text { Ciliate A swam in an irregular helical trajectory from female's A1 tip region } \\
\text { to its dorsal region for } \sim 6 \mathrm{~s} \text {, but was apparently ignored by female. }\end{array}$ & $\begin{array}{l}\text { Ciliate A: } \\
0.26-4.1\end{array}$ & $\begin{array}{l}\text { Ciliate A: } \\
>5.97\end{array}$ & $\begin{array}{l}\text { Ciliate A: } \\
\quad \text { No }\end{array}$ \\
\hline & $\begin{array}{l}\text { Ciliate B swam unidirectionally and rather constantly from female's dorsal to } \\
\text { its anterior region, passed by female's A1 tip, and was captured immediately. }\end{array}$ & Ciliate B: & $\begin{array}{l}\text { Ciliate B: } \\
\quad 1.44\end{array}$ & $\begin{array}{l}\text { Ciliate B: } \\
\text { Yes }\end{array}$ \\
\hline 16 & $\begin{array}{l}\text { Ciliate swam along a curved trajectory towards the lateral-dorsal side of } \\
\text { female and was captured just before bumping into female. }\end{array}$ & $4.2-5.9$ & 0.80 & Yes \\
\hline 17 & $\begin{array}{l}\text { Ciliate swam rather unidirectionally and constantly towards female's } \\
\text { lateral region. }\end{array}$ & $1.9-3.1$ & 0.43 & Yes \\
\hline 18 & $\begin{array}{l}\text { Ciliate swam quickly and rather unidirectionally and passed by female's } \\
\text { mouthparts. }\end{array}$ & $7.5-9.3$ & 0.30 & No \\
\hline 19 & $\begin{array}{l}\text { Ciliate swam rather unidirectionally and constantly towards female's } \\
\text { mouthparts. }\end{array}$ & $3.5-5.2$ & 0.67 & Yes \\
\hline $\begin{array}{l}20 \\
\text { (Fig. 3g) }\end{array}$ & Ciliate accelerated from 0 velocity and swam towards female's mouthparts. & $0.0-5.9$ & 0.27 & Yes \\
\hline 21 & Ciliate accelerated from 0 velocity and quickly passed by female's A1 tip. & $0.0-5.1$ & 0.13 & Yes \\
\hline 22 & $\begin{array}{l}\text { Ciliate accelerated from } 0 \text { velocity, swam perpendicularly towards female's } \\
\text { A1 front portion, soon turned downward and zigzagged ventrally to } \\
\text { female's mouthparts. }\end{array}$ & $0.0-4.2$ & 0.47 & Yes \\
\hline $\begin{array}{l}23 \\
\text { (Fig. 3h) }\end{array}$ & $\begin{array}{l}\text { Ciliate circled nearby female's eggsac region at } \sim 0.17 \mathrm{~s} \mathrm{cycle}^{-1} \text { for a few } \\
\text { seconds. }\end{array}$ & $1.3-3.1$ & $>1.53$ & No \\
\hline 24 & $\begin{array}{l}\text { Ciliate accelerated from } 0 \text { velocity at female's dorsal side and quickly swam } \\
\text { from female's urosome to its anterior region. }\end{array}$ & $0.0-9.2$ & 0.27 & No \\
\hline $\begin{array}{l}25 \\
\text { (Fig. 3i) }\end{array}$ & $\begin{array}{l}\text { Ciliate swam quickly and rather unidirectionally and bumped into female's } \\
\text { urosome. }\end{array}$ & $4.6-9.4$ & 0.23 & Yes \\
\hline (Fig. 31) & $\begin{array}{l}\text { In this event, the prey items were } 2 \text { copepod nauplii: Nauplius A jumped } \\
\text { intermittently and bumped into one branch of female's caudal rami, but } \\
\text { was apparently ignored; } 0.3 \mathrm{~s} \text { later, Nauplius B swam along a curved } \\
\text { trajectory towards female's A } 1 \text { tip and was immediately captured } \\
\text { by female. }\end{array}$ & $\begin{array}{c}\text { Nauplius A: } \\
5.9-7.6 \\
\text { Nauplius B: } \\
0.6-8.6\end{array}$ & $\begin{array}{c}\text { Nauplius A: } \\
0.77 \\
\text { Nauplius B: } \\
0.50\end{array}$ & $\begin{array}{l}\text { Nauplius A: } \\
\text { No } \\
\text { Nauplius B: } \\
\text { Yes }\end{array}$ \\
\hline
\end{tabular}



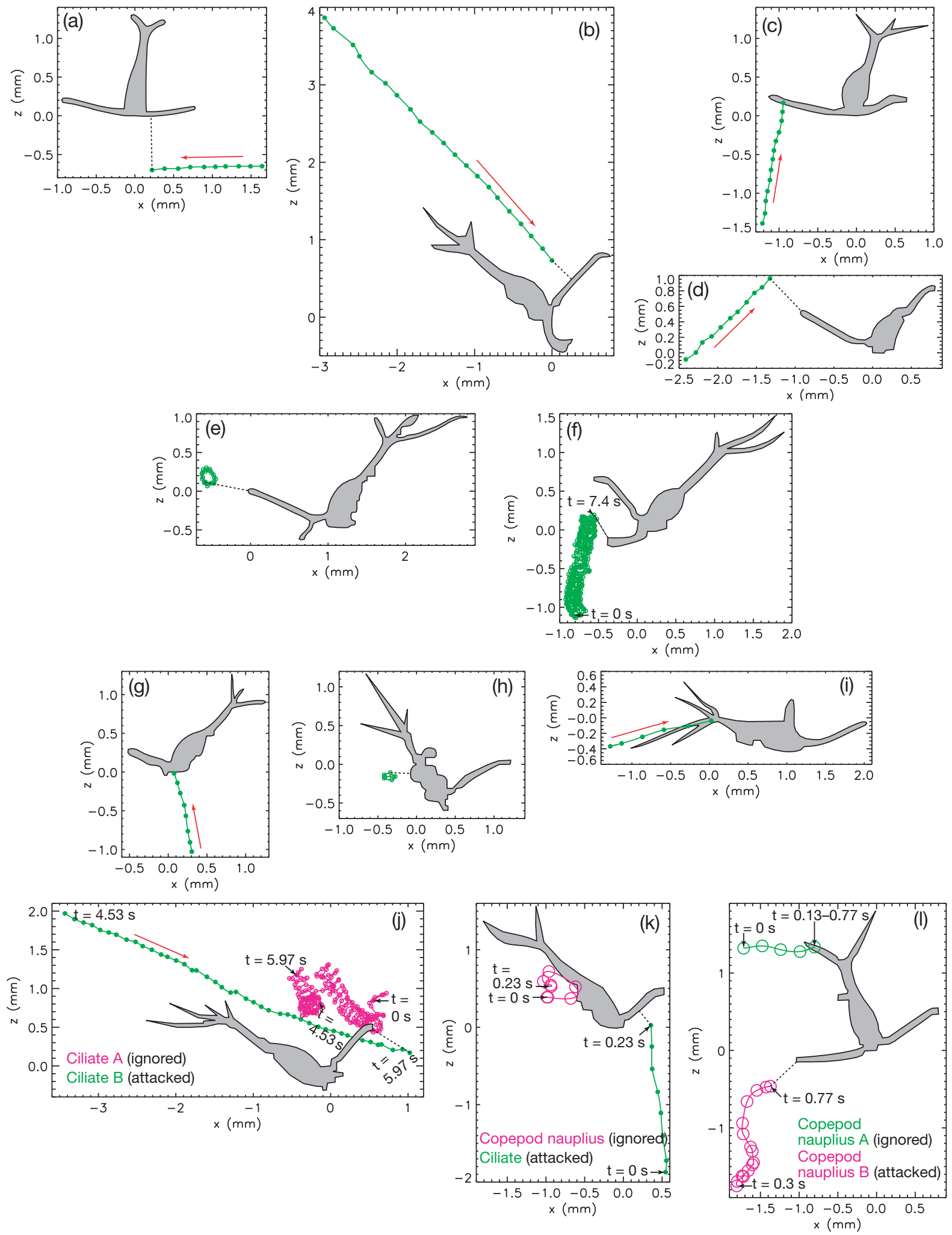

Fig. 3. Oithona plumifera. Samples $(\mathrm{n}=12)$ of observed encounters between females and swimming ciliates Strobilidium spp. Illustrations were constructed by overlapping a series of video sequences relative to a similar frame of reference fixed on the female. Small green circles connected by a solid green line represent the instantaneous positions and trajectory of the swimming ciliate, with the positions marked every $1 / 30 \mathrm{~s}$ (except for (e) in which the positions were marked every $1 / 60 \mathrm{~s}$ ). Red arrowed lines indicate the general swimming direction of the ciliate; short dashed lines represent the reaction distance; $\mathrm{x}$ is the horizontal direction of the focus plane; and $\mathrm{z}$ is the vertical coordinate (positive upward) 
Table 3. Oithona plumifera. Measured behavioral characteristics of adult females preying on swimming ciliates Strobilidium spp. (characteristics are defined in Fig. 1 \& Table 1)

\begin{tabular}{|c|c|c|c|c|c|c|c|}
\hline Event \# & $u_{\text {ciliate }}\left(\mathrm{mm} \mathrm{s}^{-1}\right)$ & $d_{\mathrm{rc}}(\mathrm{mm})$ & $\theta_{\mathrm{b}, \mathrm{rc}}\left({ }^{\circ}\right)$ & $R(\mathrm{~mm})$ & $U_{\text {attack }}\left(\mathrm{mm} \mathrm{s}^{-1}\right)$ & $d_{\mathrm{rr}}(\mathrm{mm})$ & $\theta_{\mathrm{bb}}\left({ }^{\circ}\right)$ \\
\hline 1 (Fig. 3a) & 4.89 & 0.75 & 27.81 & 0.70 & 58.31 & 0.97 & 15.91 \\
\hline 2 & 0.47 & 0.28 & 24.17 & 0.30 & 19.60 & 0.33 & 15.75 \\
\hline 3 & 6.32 & 0.71 & 25.72 & 0.33 & 58.69 & 0.98 & 27.46 \\
\hline 4 & 7.25 & 0.86 & 46.09 & 0.35 & 80.83 & 1.58 & 15.23 \\
\hline 5 (Fig. 3b) & 5.82 & 0.74 & 129.03 & 0.35 & 29.17 & 0.49 & 121.84 \\
\hline 6 & 4.91 & 0.50 & 45.02 & 0.32 & 50.37 & 0.84 & 27.05 \\
\hline 7 (Fig. 3c) & 3.46 & 0.85 & 80.04 & 0.00 & 43.35 & 0.86 & 3.01 \\
\hline 8 & 6.33 & 0.34 & $\mathrm{NA}^{\mathrm{a}}$ & 0.21 & 13.16 & 0.22 & $\mathrm{NA}^{\mathrm{a}}$ \\
\hline 9 (Fig. 3k) & 8.28 & 0.36 & 48.51 & 0.24 & 43.21 & 0.72 & 84.76 \\
\hline 10 (Fig. 3d) & 4.60 & 1.57 & 79.92 & 0.58 & 87.50 & 1.75 & 56.89 \\
\hline 11 & 2.74 & 1.81 & 92.30 & 0.71 & 100.91 & 1.68 & 112.94 \\
\hline 12 (Fig. 3e) & 1.68 & 1.68 & 74.11 & 0.57 & 126.56 & 2.11 & 86.79 \\
\hline 13 & 0.58 & 1.34 & 132.46 & 0.18 & 70.34 & 1.17 & 126.04 \\
\hline 14 (Fig. 3f) & 1.00 & 0.64 & 64.11 & 0.34 & 45.37 & 0.76 & 82.01 \\
\hline 15 (Fig. 3j) & 1.32 & 1.19 & 50.07 & 0.56 & 87.41 & 1.42 & 9.43 \\
\hline 16 & 4.45 & 0.37 & 138.46 & 0.07 & 42.93 & 0.72 & 96.52 \\
\hline 17 & 3.12 & 0.49 & 153.84 & 0.18 & 53.65 & 0.89 & 96.17 \\
\hline 18 & 7.53 & 1.24 & 137.25 & 0.63 & 59.68 & 0.99 & 123.38 \\
\hline 19 & 4.82 & 0.00 & 0.00 & 0.00 & 0.00 & 0.00 & 0.00 \\
\hline 20 (Fig. 3g) & 3.89 & 0.00 & 0.00 & 0.00 & 0.00 & 0.00 & 0.00 \\
\hline 21 & 5.07 & 1.08 & 63.94 & 0.51 & 82.38 & 1.37 & 35.10 \\
\hline 22 & 2.67 & 0.54 & 125.79 & 0.26 & 19.85 & 0.33 & 85.78 \\
\hline 23 (Fig. 3h) & 2.54 & 0.81 & 152.37 & 0.26 & 48.02 & 0.80 & 85.39 \\
\hline 24 & 9.19 & 0.19 & $\mathrm{NA}^{\mathrm{a}}$ & 0.05 & 5.20 & 0.11 & $\mathrm{NA}^{\mathrm{a}}$ \\
\hline 25 (Fig. 3i) & 9.32 & 1.13 & 180.00 & 0.00 & 95.92 & 1.51 & 175.20 \\
\hline 26 (Fig. 3l) $^{\mathrm{b}}$ & 1.73 & 1.43 & 92.36 & 0.75 & 100.49 & 1.67 & 130.61 \\
\hline Mean $\pm \mathrm{SD}$ & $4.38 \pm 2.59$ & $0.80 \pm 0.51$ & $81.81 \pm 51.61$ & $0.33 \pm 0.24$ & $54.73 \pm 33.94$ & $0.93 \pm 0.58$ & $67.22 \pm 50.85$ \\
\hline
\end{tabular}

Table 4. Oithona plumifera. Mean $( \pm \mathrm{SD})$ reaction distances $(R)$ calculated respectively for 3 subgroups of the 25 analyzed encounters between adult females and the ciliates Strobilidium spp.

\begin{tabular}{|lc|}
\hline Subgroup & $R(\mathrm{~mm})$ \\
\hline Events \#1 to $\mathbf{1 5}$ & $0.38 \pm 0.20$ \\
A1 was the sensory region, and the ciliate concentration was 3.4 ciliates $\mathrm{ml}^{-1}$ & \\
Events \#16 to $\mathbf{1 9}$ & $0.22 \pm 0.28$ \\
Mouthparts or prosome were the sensory region, and the ciliate concentration was $3.4{\text { ciliates } \mathrm{ml}^{-1}}^{\text {Events \#20 to } \mathbf{2 5}}$ & $0.18 \pm 0.20$ \\
Ciliate concentration was 21 ciliates $\mathrm{ml}^{-1}$ for Events \#20, 21 and $25 ; 18.4$ ciliates $\mathrm{ml}^{-1}$ for Event \#24; & \\
and undetermined for Events \#22 and 23 & \\
\hline
\end{tabular}

approximately at $1 / r^{3}$ lateral to the ciliate and slightly slower than $1 / r^{3}$ but much faster than $1 / r^{2}$ in front of the ciliate (Fig. 7a,d). In cases where either a single flagellum trails the body (Fig. 2b), the posterior surface of the ciliate body is covered by cilia (Fig. 2c), or the anterior surface of the ciliate is covered by cilia (Fig. 2e), the flow is dipole-like (Figs. 5b,c,e \& 6b,c,e), but decays faster than $1 / r^{2}$ (Fig. 7b,c,e). A distinct property of the latter 3 cases is the much greater flow velocities at the region where the ciliary forcing is located than the swimming velocity of the ciliate. This property is absent in the 2 former cases. More interestingly, anterior ciliary forcing differs from the other 4 cases in that the flow direction, a short distance away and in front of the ciliate, is opposite to its swimming direction (Fig. 5e). This flow could be regarded as a feeding current as it may displace food particles towards the ciliate. Thus, the details of ciliary forcing do matter. 

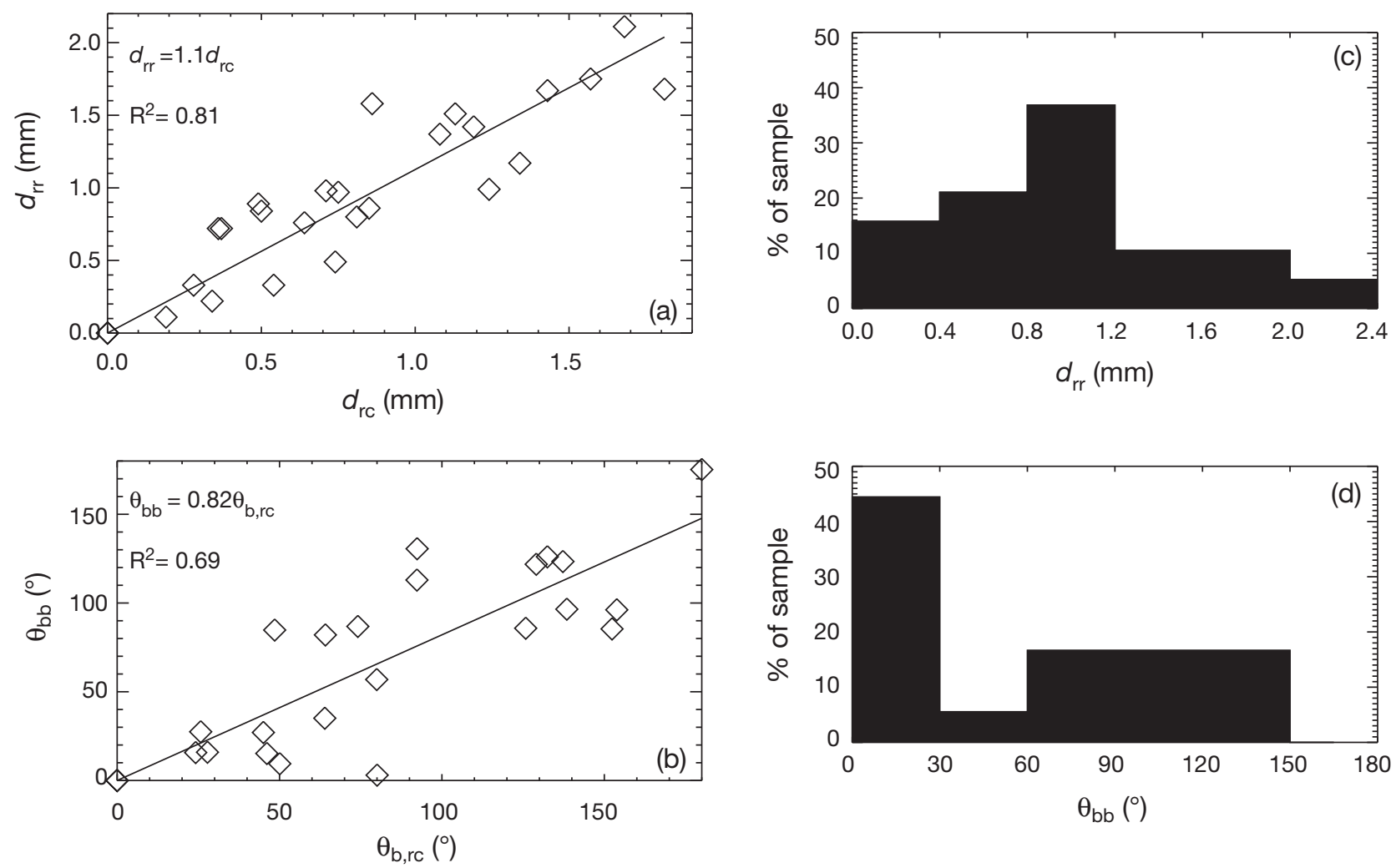

Fig. 4. Oithona plumifera. Behavioral characteristics of attacks made by females on swimming ciliates: (a) $d_{\mathrm{rr}}$ vs. $d_{\mathrm{rc} r}$ (b) $\theta_{\mathrm{bb}}$ vs. $\theta_{\mathrm{b}, \mathrm{rc}}(\mathrm{c})$ frequency of $d_{\mathrm{rr}}$, and (d) frequency of $\theta_{\mathrm{bb}}$, for encounter events with a ciliate concentration of 3.4 ciliates ml ${ }^{-1}$. Behavioral characteristics are defined in Table 1 and shown in Fig. 1, and the measured data are provided in Table 3

\section{Modeling of representative hydrodynamic signal fields}

Despite the above discrepancies, we may still use the CFD results to calibrate the stresslet strength to come up with a calibrated stresslet model for approximating the flow created by a model Strobilidium ciliate (Figs. 5 e \& 6e). The far-field flow decay rate does not really matter. What matters is the bulk level of the flow disturbance within the detection range ( 10 to $30 \mathrm{a}$ from the center of the ciliate based on our observations). Results of the CFD modeling and of the stresslet model are quite similar in terms of the flow pattern in front of, and behind, the swimming cell. As a result, we chose a stresslet strength of $12 \pi \mu a^{2} U(=6 \pi \mu a U \times 2 a)$, and obtained a stresslet flow field which is similar to that in the CFD model in terms of both the bulk level of flow disturbance and the flow pattern in front of and behind the swimming ciliate (Fig. 6 g vs. Fig. 6e). Additionally, to consider the feeding current type of flow shown in Fig. 5e, the 2 point forces in the stresslet model were applied such that they were directed towards each other. We used this calibrated stresslet model to quantify the spatio-temporal hydrodynamic signals created by a ciliate swimming near an Oithona plumifera female, i.e. we 'painted' the stresslet flow disturbances onto the observed trajectory of the ciliate. If we chose a stresslet strength of $0.6 \pi \mu a^{2} U(=6 \pi \mu a U \times 0.1 a)$ instead, we would end up with a much weaker stresslet flow field (Fig. 6f vs. Fig. 6g), which, nevertheless, has the same bulk level of flow velocities as those shown in Fig. 6a,d.

We present several representative hydrodynamic signal fields out of the 26 analyzed encounter events. Each signal field is shown as velocity vector plots at 3 time instants throughout the encounter period (Fig. 8). The modeled flow disturbance field is 3D; however, the results are shown on the focal plane where both the swimming trajectory of the ciliate and the profile of the sensory region of the copepod were approximately located. The 1 st spatio-temporal pattern of the signal field consisted of a nearly constant flow structure sweeping over the copepod's sensory region(s), such as the one shown in Fig. 8a, in which the ciliate swam nearly steadily parallel to the front portion of the copepod's A1 (Event \#1, Fig. 3a). Assuming that the 3 hypothetical A1 setae (also shown in Fig. 8a) exactly followed the fluid motion, the setal tips 


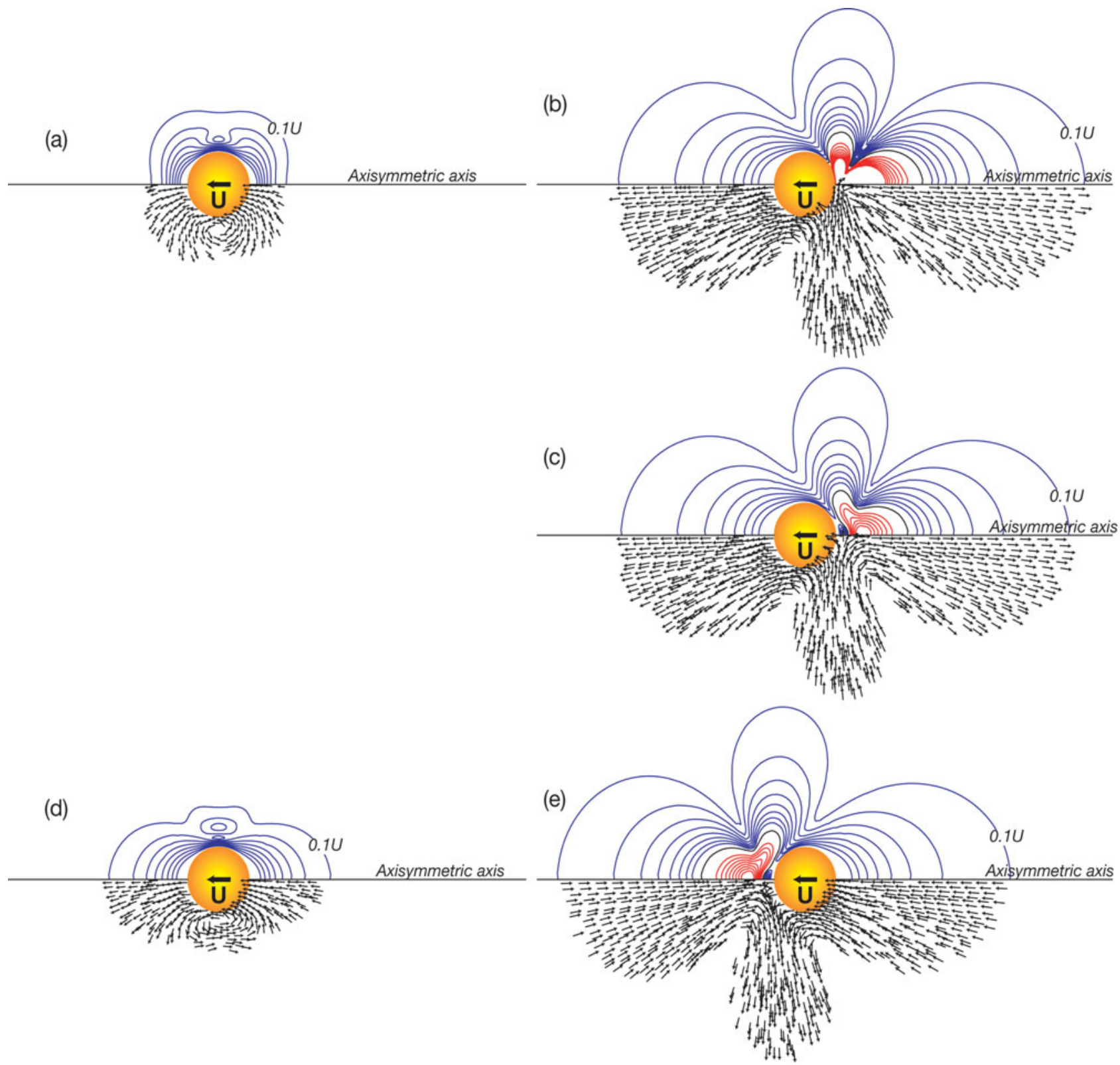

Fig. 5. Near-field flow distributions corresponding to the 5 ciliary forcing schemes presented in the same order as (a) to (e) in Fig. 2. A stationary frame of reference is used so that velocity at the cell surface is $\mathbf{U}$ (i.e. the swimming velocity vector). Plotted in the meridian plane above the axisymmetric axis are contours of flow velocity magnitudes: black contour lines indicate flow velocity magnitudes equal to the ciliate swimming speed $U$, blue contours show flow velocity magnitudes $<U$ (minimum $=0.1 U$, with increment $=0.1 U$ ), and red contours indicate flow velocity magnitudes $>U$ (minimum $=1.5 U$, with increment $=0.25 U$ ). Plotted in the meridian plane below the axisymmetric axis are equal-length flow velocity vectors showing flow directions, plotting only vectors with magnitudes $>0.1 U$

should have initially been bent rightwards and then turned back one by one as the ciliate passed by them one by one. Such a simple motion pattern of the setae should have been easily recognizable. The 2 nd pattern was highly unsteady as the ciliate performed circling motions near a sensory region (Event \#12, Fig. 3e; Event \#14, Fig. 3f; Ciliate A in Event \#15, Fig. 3j). Because of the highly oscillatory flow surrounding the sensory region (Fig. 8b), the A1 tip setae (also shown in Fig. 8b) should have undergone an oscillatory motion, and the copepod might have experienced difficulty in recognizing this setal motion pattern. The copepods were unable to locate the ciliates quickly and accurately, delaying, often by a few seconds, initiation of the attack (e.g. Events \#12, \#14 and \#15). The 3rd pattern, wherein the swimming path of the ciliate brought 
(a)

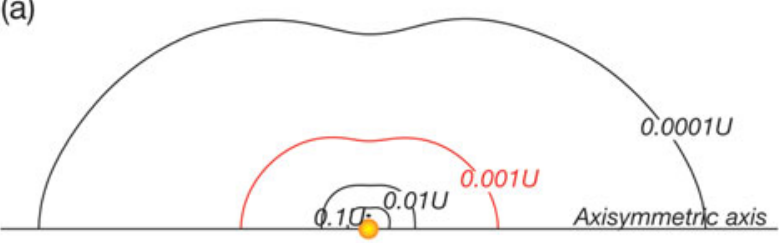

(d)

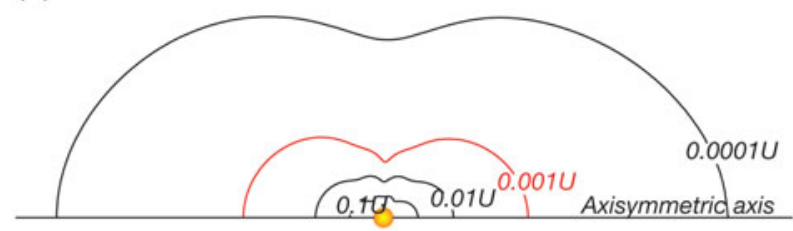

(b)

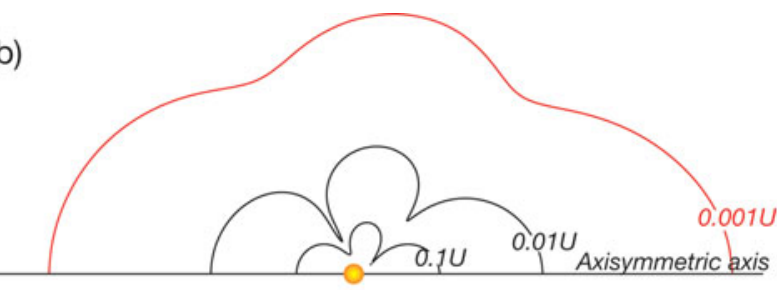

(c)

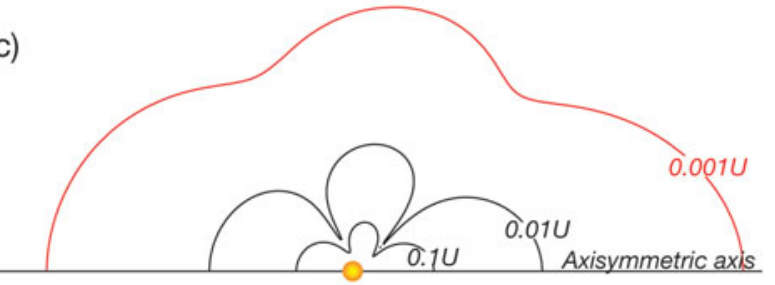

(f)

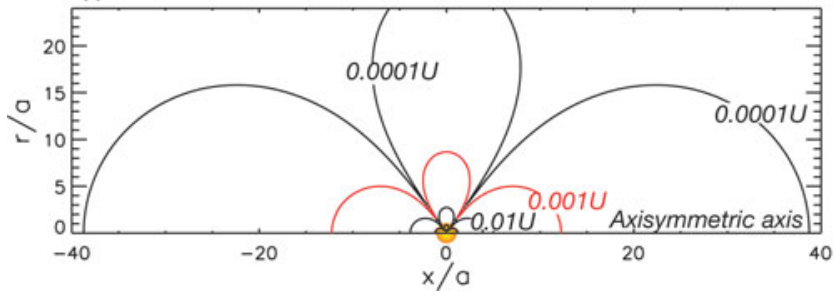

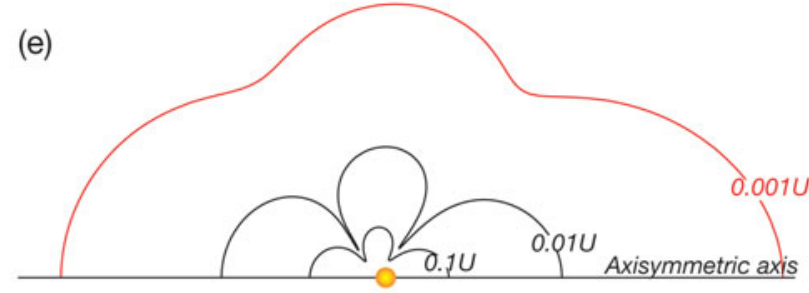

(g)

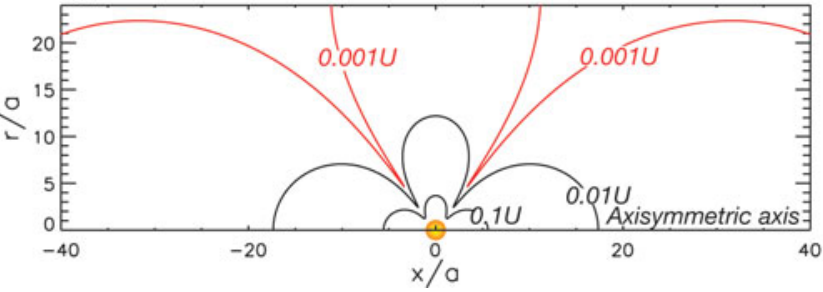

Fig. 6. Far-field flow distributions corresponding to the 5 ciliary forcing schemes presented in the same order as (a) to (e) in Fig. 2. Plotted in an axial plane are contours of flow velocity magnitudes. A stationary frame of reference is used so that velocity at the cell surface is $\mathbf{U}$ (i.e. the swimming velocity vector). Also shown are contour plots of flow velocity magnitudes associated with the stresslet model for a force-free, self-propelled, swimming microorganism. The stresslet model consists of 2 opposing point forces of equal magnitudes $(=6 \pi \mu a U$, the Stokes drag). The separation distance between the 2 point forces is: (f) $0.1 a$, and (g) $2 a$, where $a$ is the effective radius of the microorganism, the swimming speed $U=|\mathbf{U}|$, and $\mu$ is the dynamic viscosity of the fluid

it steadily closer to the copepod's sensory region (e.g. Fig. 3b-d,g,i; Ciliate in Fig. 3k), was the most common. As a result, the hydrodynamic signal steadily became stronger before the attack occurred (Fig. 8c). Most likely, the copepods were able to anticipate where the prey would end up and reacted adaptively. When the ciliate swam directly into the copepod's mouthparts (Fig. 3g) or anterior region (Fig. 3k), the copepod waited until the last moment before attacking (i.e. long after the so-called threshold signal strength was reached). When the ciliate swam towards one side of the copepod's body (e.g. Fig. 3b, and a few other events not shown), the copepod did not wait but attacked when the ciliate was still a short distance away. Such contrasting reactions could be due to attempts at effort reduction in capturing the prey. In the latter events, the copepods would have to rotate their bodies and hence spend more effort if the ciliates would bump into their body parts. Additionally, the copepods might not be able to locate the ciliates as easily as they did when the ciliates were near the A1 with their numerous setae. These encounter events support the notion that copepods pick the most opportune position possible for capturing prey. The last signal pattern had the peak signal location passing by or moving away from the copepod's sensory region (not shown). This result may be due to the ciliate's acceleration from zero velocity, reaching the peak velocity at 

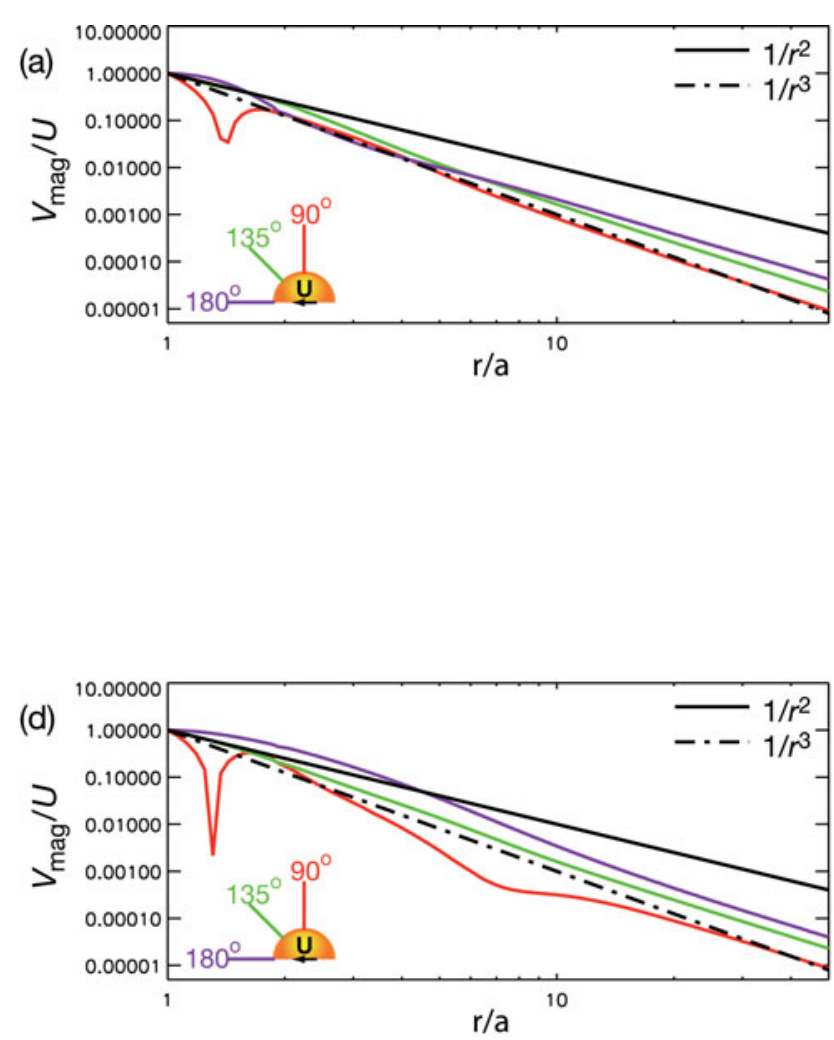
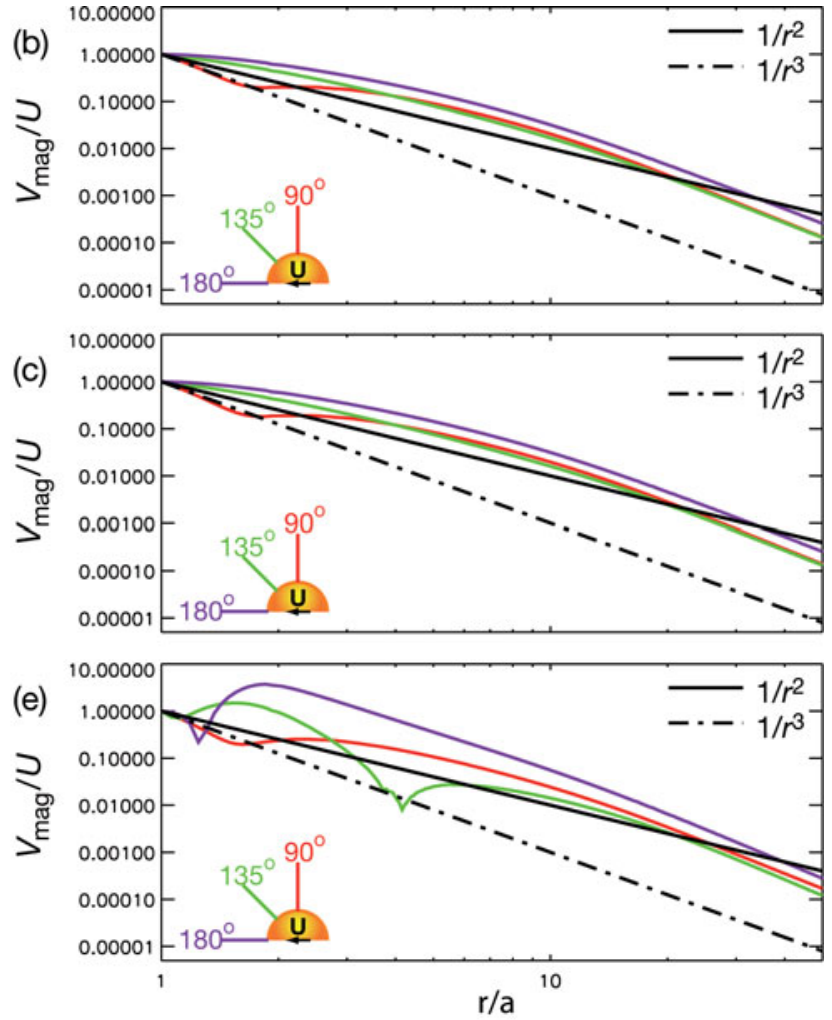

Fig. 7. Spatial decay of flow disturbances corresponding to the 5 ciliary forcing schemes presented in the same order as (a) to (e) in Fig. 2. A stationary frame of reference is used so that velocity at the cell surface is $\mathbf{U}$ (i.e. the swimming velocity vector). The flow velocity magnitudes $V_{\text {mag, }}$ normalized by the ciliate swimming speed $U$, are plotted against distance $r$ relative to the cell center, normalized by the cell radius a. Spatial decays are plotted along 3 directions as indicated by the insert in each panel. Also plotted are decay rates of $1 / r^{2}$ and $1 / r^{3}$

a later part of its swimming path. Although these 4 spatio-temporal signal patterns can generally be seen, the signal patterns for individual encounter events can vary substantially, depending on the specific encounter scenarios involved.

For each of the encounter events, one may also estimate signal strength (in terms of flow velocity at the moment just before the attack). Estimated signal strengths differed by orders of magnitude. Fig. 8a probably shows the weakest hydrodynamic signals (i.e. the tip-to-base flow velocity difference over a setal length of $350 \mu \mathrm{m}$ was $12 \mu \mathrm{m} \mathrm{s}^{-1}$, equivalent to a shear rate over the setal length of $0.034 \mathrm{~s}^{-1}$ ) to which Oithona plumifera responded by displaying a capture movement. However, the copepods did not display a capture movement even though signal strengths had reached much higher levels in other events that we had analyzed. Most likely, the copepod detected the ciliate long before attacking it. Another interesting feature in many of the encounter events was the occurrence of one or several flow reversals in individual setae of the responsible sensory region as the ciliate approached or passed by (Fig. 8).

\section{DISCUSSION}

In the present study, wide variance was found in the measured reaction distances $(0.38 \pm 0.20 \mathrm{~mm}$ [mean \pm $\mathrm{SD}$ ] using A1 as the sensory region) of Oithona plumifera females in response to swimming ciliates of the genus Strobilidium. Svensen \& Kiørboe (2000) also found mean reaction distances of $0.14 \pm 0.07 \mathrm{~mm}( \pm \mathrm{SD})$ for $O$. similis using A1 to detect the dinoflagellate Gymnodinium dominans. They used the mean of the measured reaction distances for an encounter-rate model (e.g. Svensen \& Kiørboe 2000, Visser 2001), which implied that the predator displayed behavioral responses to the prey at the approximate time when a threshold signal strength was exceeded.

However, the purpose of this study was not to construct an encounter-rate model but to explain the wide variance in our measured reaction distances. Our modeled spatio-temporal hydrodynamic signal fields (Fig. 8), which were based on empirical data inputs, show that when a prey swims near a predator, the prey-created flow disturbance field possesses a certain spatio-temporal pattern potentially perceivable by the 
(a)
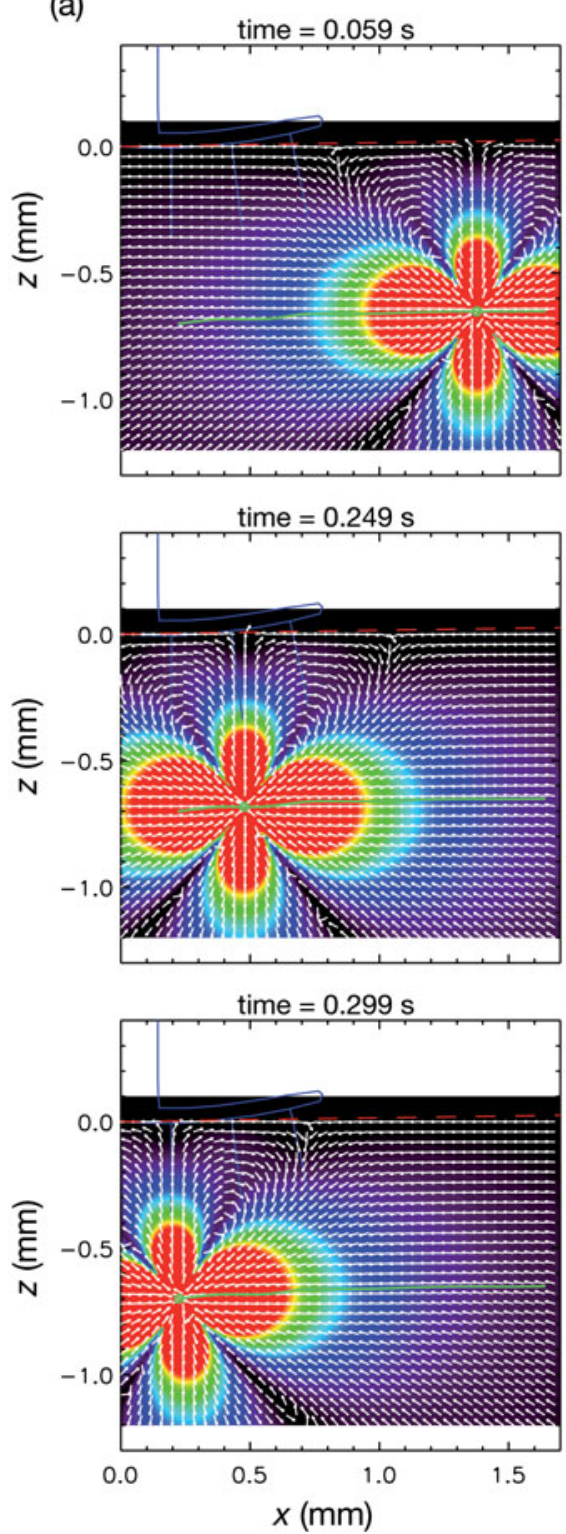

(b)
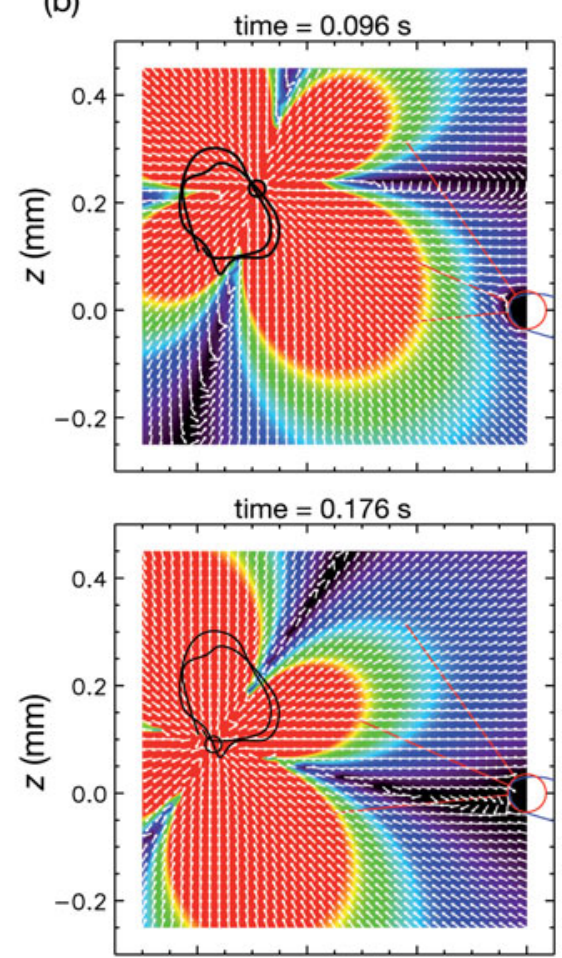

time $=0.306 \mathrm{~s}$

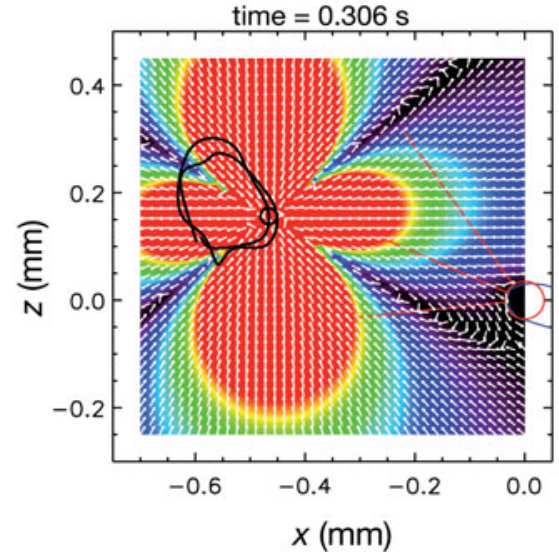

(c)
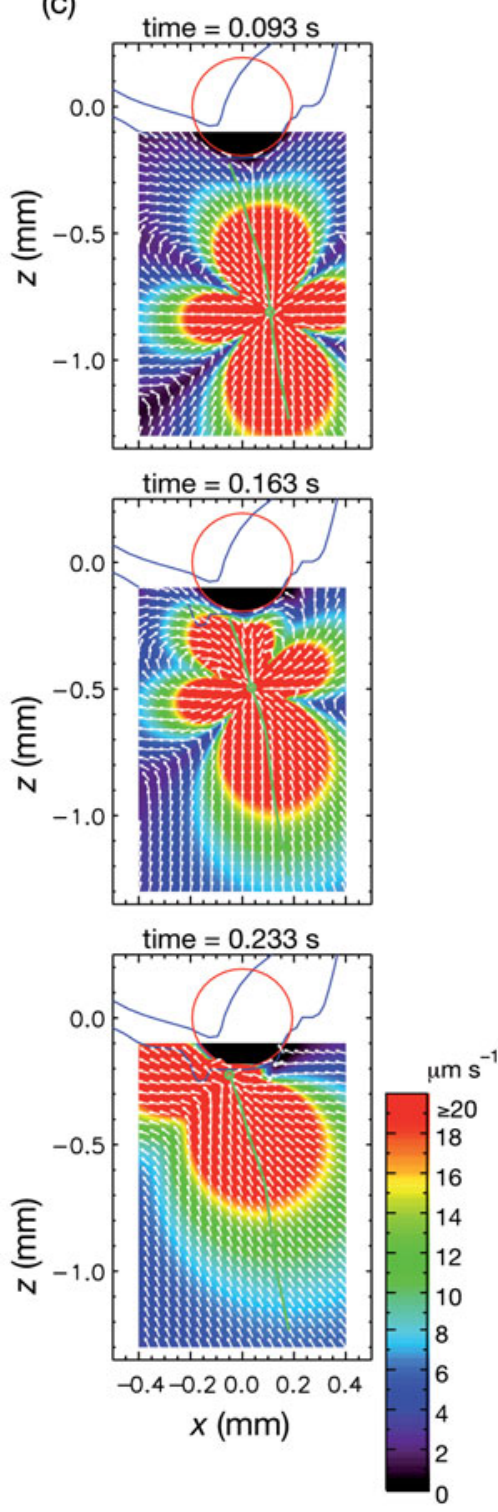

Fig. 8. Model results of the spatially/temporally varied hydrodynamic signal field created by the swimming ciliate in (a) encounter Event \#1 (Fig. 3a), (b) encounter Event \#12 (Fig. 3e), and (c) encounter Event \#20 (Fig. 3g). The instantaneous velocity vector field (uniform length vectors overlapped with color contours of flow velocity magnitude) is shown for 3 time instants. The small green circles mark the instantaneous position of the ciliate, with the solid green line as the overall trajectory. In (a), the red dashed lines represent the plane wall which approximates the solid boundary imposed by the A1 (the sensory region) front portion. Three hypothetical A1 setae (350 $\mu \mathrm{m}$ in length) are also shown as blue solid lines. In (b), the red circles represent the sphere which approximates the solid boundary imposed by the A1 tip, and positions of 3 representative A1 setae (350 $\mu \mathrm{m}$ in length) are also shown as red solid lines. In (c), the red circles represent the sphere which approximates the solid boundary imposed by the copepod's anterior and mouthparts. See Fig. 3 for definitions of $\mathrm{x}$ and $\mathrm{z}$

predator. Such a pattern is encounter-scenario dependent and is determined by the prey's swimming behavior (velocity and trajectory) relative to the predator's sensory morphology (which imposes a boundary condition to the prey-generated flow disturbance field). The notion is that, by monitoring the spatio-temporal pattern of the prey-generated flow disturbance field, the predator can perceive the instantaneous velocity and trajectory of the prey. This notion also implies that the predator recognizes the presence of the prey when the prey is nearby and creating a flow disturbance above a minimum required signal strength. If the predator is able to further figure out every step of the prey motion and has the intention to attack, then it should attack when the prey reaches the approximate location where it can be most easily captured. Such a 
strategy enables the predator to adopt an optimal attack angle, distance and speed for capturing the prey. By doing so, high capture success can be achieved with limited capture difficulty and effort. The surrounding water may also be less disturbed to avoid alerting the predator's own enemies. Responding at an approximately constant reaction distance does not seem to maximize the predator's capture success.

Results from the present empirical modeling study support the above-described notion. The good correlation between measured Oithona attack kinematics and measured data of the pre-attack location of the prey suggests that Oithona plumifera can locate the prey accurately and adapt its attack direction and speed.

Data show that Oithona plumifera females preferred small body rotations for attacking the ciliates. Small body rotations may reduce capture difficulty experienced and effort invested. To successfully capture a ciliate, O. plumifera has to place its mouthparts at the (exact) ciliate location it detects presumably at the time just before it initiates the attack, as in the findings of Svensen \& Kiørboe (2000) on O. similis females. The A1 front portion is the place where $O$. plumifera needs only a nearly effortless hop to capture the ciliate. The A1 tip region, the region surrounding the mouthparts and the 2 sides of the body pose medium difficulty as they require $O$. plumifera to turn its body by a small angle and jump towards the prey unless the prey swims directly into the predator's mouthparts. O. plumifera faces the highest difficulty when a ciliate is located at an awkward place such that the copepod has to rotate its body by $\sim 90$ to $180^{\circ}$ and jump energetically in order to grasp the ciliate. Sometimes, the copepod's effortful jumping displaces the ciliate from its detected location, leading to a failed capture attempt (e.g. Event \#23, Fig. 3h), although successful captures may also be possible (e.g. Event \#25, Fig. 3i). Thus, detecting prey may only be the first step (and perhaps the easiest). The next step is to perceive and project the swimming trajectory of the prey over an extended interval. The final step is to time the attack when the prey reaches a location where it can be most easily captured. As shown by the present observations, O. plumifera quickly perceived ciliates that were moving in 1D (e.g. Event \#1, Fig. 3a). In contrast, ciliates swimming in 2D or 3D (i.e. circles or spirals, e.g. Event \#14, Fig. 3f) were more difficult to perceive and locate, requiring the copepod to delay decision making.

The hydrodynamic modeling has revealed that estimated ciliate-created hydrodynamic signal strengths just prior to attack were all above a minimum required signal level but were substantially different from each other. Combined with the wide variance in measured reaction distances and the observation that Oithona plumifera waited for ciliates to arrive at their mouthparts, this result suggests that $O$. plumifera detected the existence of the ciliate long before attacking it. Thus, it can be misleading to consider only the threshold signal strength without assessing the spatio-temporal signal patterns. O. plumifera females displayed strong adaptive behaviors to perceived spatio-temporal patterns of ciliate-created hydrodynamic signal fields.

As exemplified by 3 encounter events, Oithona plumifera chose the prey that was easier to locate when it encountered 2 motile prey simultaneously (Fig. 3j), and also chose the prey that was easier to capture because less body rotation was involved in the attack (Fig. 3k,1). In view of these observations, O. plumifera females may be better characterized as saltatory foragers, as 'prey choice is unlikely for cruise or ambush searchers' (O'Brien et al. 1990, p. 158). Also, cruise or ambush searchers monitor the outer boundary of the search space and strike a prey almost as soon as it is perceived. In contrast, O. plumifera females first scanned the entire search space while stationary, attacked both prey arriving at the outer boundary and those starting to move near their sensory regions, or waited to attack prey until it reached the best location possible for capture.

The CFD modeling shows that the flow pattern and spatial decay of hydrodynamic disturbances created by a neutrally buoyant, swimming protist are sensitive to the way the protist propels itself, and especially to its distribution of propulsive forces over the surrounding water. Flow patterns and spatial decay of hydrodynamic disturbances by prey are thus species-specific. This raises the possibility of the predator recognizing the flow pattern and spatial decay and using this information to distinguish among different prey species. A sinking diatom may create a stronger flow disturbance than a swimming protist of the same size range $(\mathrm{H}$. Jiang unpubl. results). However, the two may differ in the signal patterns that may be perceived by the predator.

The stresslet model decays more slowly with distance than the flow created by a neutrally buoyant, swimming protist. However, it may still be adequate to use the stresslet model for some species that create dipole-like flow patterns, provided that stresslet strength is calibrated. Some other species may create non-dipole-like flow patterns. For dinoflagellates that possess both a transversal and a longitudinal trailing flagellum, the associated flow may be reproduced by combining the equatorial forcing scheme (Fig. 2d) and the trailing forcing scheme (Fig. 2b). Flow pattern and spatial decay rate can vary greatly depending on the relative contributions of the 2 flagella to thrust.

Oithona plumifera occurs abundantly not only on outer shelves but also in the epipelagial of subtropical and tropical open waters where ciliates are not found as abundantly as in neritic regions. Thus, juveniles and 
females of $O$. plumifera have to depend mostly on heterotrophic flagellates and dinoflagellates of $10 \mu \mathrm{m}$ equivalent spherical diameter (ESD) or smaller (e.g. Paffenhöfer et al. 2003) whose signal strength will most likely be weaker than that of Strobilidium spp. This study has revealed a minimum required hydrodynamic signal level for $O$. plumifera females, i.e. a tip-to-base flow velocity difference of $12 \mu \mathrm{m} \mathrm{s}^{-1}$ over a setal length of $350 \mu \mathrm{m}$, which is equivalent to a shear of $0.034 \mathrm{~s}^{-1}$. Such a low threshold for signal strength appears essential for O. plumifera to obtain sufficient food for growth and survival in such a nutritionally dilute environment as the warm open ocean (Conover 1968).

Acknowledgements. The authors thank P. A. Jumars, T. Kiørboe, D. J. McGillicuddy, J. R. Strickler, and anonymous reviewers for providing insightful comments that significantly improved the final paper. This work was supported by National Science Foundation grants NSF OCE-0323055 \& OCE-0352237 to G.-A.P. and NSF OCE-0323959 \& OCE0352284 to H.J. The authors also acknowledge the support from NSF Biological Oceanography.

\section{LITERATURE CITED}

Atkinson A (1995) Omnivory and feeding selectivity in five copepod species during spring in the Bellingshausen Sea, Antarctica. ICES J Mar Sci 52:385-396

Broglio E, Johansson M, Jonsson PR (2001) Trophic interaction between copepods and ciliates: effects of prey swimming behavior on predation risk. Mar Ecol Prog Ser 220:179-186

Bundy MH, Vanderploeg HA (2002) Detection and capture of inert particles by calanoid copepods: the role of the feeding current. J Plankton Res 24:215-223

Bundy MH, Gross TF, Vanderploeg HA, Strickler JR (1998) Perception of inert particles by calanoid copepods: behavioral observations and a numerical model. J Plankton Res 20:2129-2152

> Castellani C, Irigoien X, Harris RP, Lampitt RS (2005) Feeding and egg production of Oithona similis in the North Atlantic. Mar Ecol Prog Ser 288:173-182

Conover RJ (1968) Zooplankton - life in a nutritionally dilute environment. Am Zool 8:107-118

Doall M, Strickler J, Fields D, Yen J (2002) Mapping the free-swimming attack volume of a planktonic copepod, Euchaeta rimana. Mar Biol 140:871-879

Fenchel T (1987) Ecology of Protozoa. The biology of freeliving phagotrophic protists. Science Tech Publishers/ Springer-Verlag, Madison, WI

Fields DM, Yen J (1997) Implications of the feeding current structure of Euchaeta rimana, a carnivorous pelagic copepod, on the spatial orientation of their prey. J Plankton Res 19:79-95

Fields DM, Shaeffer DS, Weissburg MJ (2002) Mechanical and neural responses from the mechanosensory hairs on the antennule of Gaussia princeps. Mar Ecol Prog Ser 227: 173-186

Gallienne CP, Robins DB (2001) Is Oithona the most important copepod in the world's oceans? J Plankton Res 23: $1421-1432$

Hausmann K, Hülsmann N, Radek R (2003) Protistology. Schweizerbart'sche Verlagsbuchhandlung, Stuttgart

> Jiang HS, Paffenhöfer GA (2004) Relation of behavior of

Editorial responsibility: Hans Heinrich Janssen,

Oldendorf/Luhe, Germany copepod juveniles to potential predation by omnivorous copepods: an empirical-modeling study. Mar Ecol Prog Ser 278:225-239

Jiang HS, Meneveau C, Osborn TR (1999) Numerical study of the feeding current around a copepod. J Plankton Res 21:1391-1421

Keller SR, Wu TY, Brennen C (1975) A traction-layer model for ciliary propulsion. In: Wu TYT, Brokaw CJ, Brennen C (eds) Proc Symp Swimming and Flying in Nature. California Institute of Technology, Pasadena, California, Jul 8-12, 1974. Plenum Press, New York, p 253-271

Kerfoot WC (1978) Combat between predatory copepods and their prey: Cyclops, Epischura, and Bosmina. Limnol Oceanogr 23:1089-1102

Kiørboe T, Visser AW (1999) Predator and prey perception in copepods due to hydromechanical signals. Mar Ecol Prog Ser 179:81-95

> Montagnes DJS, Taylor FJR (1994) The salient features of five marine ciliates in the Class Spirotrichea (Oligotrichia), with notes on their culturing and behaviour. J Eukaryot Microbiol 41:569-586

> Nakamura Y, Turner JT (1997) Predation and respiration by the small cyclopoid copepod Oithona similis: how important is feeding on ciliates and heterotrophic flagellates? J Plankton Res 19:1275-1288

O'Brien WJ, Browman HI, Evans BI (1990) Search strategies in foraging animals. Am Sci 78:152-160

Paffenhöfer GA (1993) On the ecology of marine cyclopoid copepods (Crustacea, Copepoda). J Plankton Res 15:37-55

Paffenhöfer GA (1998) On the relation of structure, perception and activity in marine planktonic copepods. J Mar Syst 15:457-473

Paffenhöfer GA, Mazzocchi MG (2002) On some aspects of the behavior of Oithona plumifera (Copepoda: Cyclopoida). J Plankton Res 24:129-135

Paffenhöfer GA, Tzeng M, Hristov R, Smith CL, Mazzocchi MG (2003) Abundance and distribution of nanoplankton in the epipelagic subtropical/tropical open Atlantic Ocean. J Plankton Res 25:1535-1549

Pozrikidis C (1992) Boundary integral and singularity methods for linearized viscous flow. Cambridge University Press, Cambridge

Strickler JR (1975) Intra- and interspecific information flow among planktonic copepods: receptors. Verh Int Verein Limnol 19:2951-2958

Strickler JR, Bal AK (1973) Setae of the first antennae of the copepod Cyclops scutifer (Sars): their structure and importance. Proc Natl Acad Sci USA 70:2656-2659

Svensen C, Kiørboe T (2000) Remote prey detection in Oithona similis: hydromechanical versus chemical cues. J Plankton Res 22:1155-1166

> Visser AW (2001) Hydromechanical signals in the plankton. Mar Ecol Prog Ser 222:1-24

Wu TY (1976) Fluid mechanics of ciliary propulsion. In: Chang TS (ed) Recent advances in engineering science, Vol 7. Scientific Publication, Boston, MA, p 289-298

> Wu TY (1977) Hydrodynamics of swimming at low Reynolds numbers. Fortschr Zool 24:149-169

> Yen J, Strickler JR (1996) Advertisement and concealment in the plankton: what makes a copepod hydrodynamically conspicuous? Invertebr Biol 115:191-205

Yen J, Lenz PH, Gassie DV, Hartline DK (1992) Mechanoreception in marine copepods: electrophysiological studies on the first antennae. J Plankton Res 14:495-512

Zaret RE (1980) Zooplankters and their interactions with water, with each other, and with their predators. PhD thesis, John Hopkins University, Baltimore, MD

Submitted: March 26, 2008; Accepted: September 22, 2008

Proofs received from author(s): December 8, 2008 